\title{
PROGRAMAS Y LENGUAJES RADIOFÓNICOS EN EL CONTEXTO SOCIAL ACTUAL
}

\author{
Pastora Moreno Espinosa \\ (Universidad de Sevilla) \\ pamoreno@us.es
}

\section{Resumen:}

El lenguaje que a diario usan los periodistas en todos los medios de Comunicación ha preocupado a los estudiosos, fundamentalmente, desde el principio de los tiempos. La programación radiofónica supone la planificación de unos contenidos ordenados, según unos criterios de selección, organizados por una empresa de radio en relación con la audiencia. Además, requiere una buena planificación a corto, medio y largo plazo de los mensajes que se deseen transmitir, entendiendo como tal la planificación de una relación comunicativa entre una empresa de radio y una audiencia mediante unos contenidos sistematizados y elaborados según una duración y unos horarios, que tienden a la especialización. Partiendo del medio radiofónico y de cómo se entiende en la actualidad, donde los medios de comunicación de masas tienen tanta importancia, analizamos en este artículo la función de la radio en la sociedad a través del lenguaje, la programación y los servicios que presta a los oyentes.

Palabras clave: Información, lenguaje, opinión, gramática, oral.

\begin{abstract}
:
The language used daily by journalists in all media of communication has preoccupied scholars mainly from the beginning of time. The radio programming involves planning some contents sorted, according to selection criteria, a company organized by radio in connection with the audience. In addition, it requires good planning in the short, medium and long-term message you want to convey, meaning the planning of a communicative relationship between a company and a radio audience through some content systematized and developed according to a few hours duration and, which tend to specialize. Starting middle radio and how it is now, where the media are so important, in this article we look at the role of radio in society through language, programming and services to the listeners.
\end{abstract}

Key words: Information, language, opinion, grammar, oral.

\section{INTRODUCCIÓN}

a información fue, en principio y necesariamente, oral. No había otra alternativa. Quien conocía la tradición tenía la palabra y quien tenía la palabra tenía el poder. Con el paso de los años, aún sigue siendo igual, aunque bajo otros as- 
pectos culturales que no son más que la consecuencia de un mundo que ya está bajo los efectos de veinte siglos de experiencia. Poco a poco, la comunicación de masas ha empezado a proclamarse, desarrollando sus afiladas armas para convertirse en lo que es hoy día: un baluarte de poder, consecuencia a la que se ha llegado, entre otras muchas cosas, gracias a la labor realizada por uno de los grandes filones de nuestra era: la radio.

La emisión de buenos programas especializados para un público heterogéneo puede incentivar el deseo de superar el nivel cultural y el desarrollo de la sociedad o simplemente adquirir una perspectiva nueva sobre determinadas parcelas de la vida cotidiana, como ocurriría con los programas de cine, pintura o literatura. En estos momentos, la especialización de los medios, ya sean electrónicos o impresos, es una clara tendencia de la comunicación moderna y de los medios que la hacen posible.

La programación radiofónica requiere una buena planificación a corto, medio y largo plazo de los mensajes que se deseen transmitir, entendiendo como tal la planificación de una relación comunicativa entre una empresa de radio y una audiencia mediante unos contenidos sistematizados y elaborados según una duración y unos horarios, que tienden a la especialización.

Y es que la radio debe estar atenta a los cambios en los hábitos de los oyentes. Es evidente que estamos en una sociedad que cambia continuamente, que no tiene tiempo para nada, que va con prisas. La radio ha sabido adaptarse a este cambio mejor aún que la televisión, ya sea por los cambios tecnológicos o por la propia personalidad del medio.

La programación radiofónica supone la planificación de unos contenidos ordenados, según unos criterios de selección, organizados por una empresa de radio en relación con la audiencia.

Programa y género radiofónico son dos conceptos diferentes que se complementan. Así, en un programa radiofónico podemos encontrar diferentes géneros, al mismo tiempo que un género puede aparecer en distintos programas y adquirir, dependiendo de ese continente, características específicas. Esos rasgos se refieren fundamentalmente al tiempo que se le destina a las informaciones y a la estructura que pueden adoptar. No obstante, también se observa la tendencia a que un género predomine más en un espacio que en otro.

Todos los estudiosos coinciden en que cada programa posee una estructura específica y un estilo propio. Partiendo de estas características, Arturo Merayo realiza la siguiente definición:

Programa de radio es un tiempo cuyos límites han sido previamente determinados -y habitualmente sometidos a una cierta periodicidad-durante el que se difunden, bajo un mismo título, mensajes que en sí mismos y en su presentación formal mantienen una unidad de criterio y se adaptan con calidad a las peculiaridades del canal radiofónico" (Merayo, 2000: 238). 
Del mismo modo, podemos establecer una tipología de los principales programas informativos:

Flash-Noticia: Flash es un concepto que procede del inglés y que ha sido traducido literalmente como relámpago, lo que nos puede dar idea de la brevedad e inmediatez de este informativo que ofrece los datos básicos de un acontecimiento. Francisco Sanabria duda si realmente se puede considerar programa, puesto que, en su opinión, "constituye más bien una interrupción de la programación ordinaria para anticipar una noticia cuya importancia justifiquen esa ruptura de lo previsto en la parrilla" (Sanabria, 1994: 113).

José Javier Muñoz y César Gil lo definen como el adelanto breve de una noticia: "la expresión o lectura de los primeros detalles que se conocen de un acontecimiento y que posteriormente serán ampliados a medida que se obtengan nuevos datos y se tratarán con la extensión que merezca y la importancia del hecho en el servicio informativo inmediatamente posterior" (Muñoz y Gil, 1994: 66).

Son estas características las que han llevado a los dos autores a considerar el flash como un subgénero de la noticia, puesto que se informa de una manera inmediata del hecho. El carácter de urgencia que supone este programa implica también una redacción rápida de la información. En estas ocasiones importa más la inmediatez que la precisión. Sin embargo, esto no es excusa para que el periodista siga ciertas normas como, por ejemplo, contrastar la información.

Existen diversas formas de introducir un flash dentro de la programación prevista. Lo más frecuente es que el presentador del programa, que será interrumpido, anuncie la noticia y dé paso al locutor, aunque también puede informar el presentador del programa. Francisco Sanabria nos ofrece un esquema básico (Sanabria, 1994: 113):

1. Interrupción, con anuncio previo del presentador del programa.

2. Sintonía habitual de los informativos para situar al oyente.

3. Flash propiamente dicho. Sólo se emplea la palabra, ya que por su rapidez no permite el uso de otros elementos.

4. Cierre de la persona que conduzca el programa interrumpido. Es un comentario breve de la noticia.

5. De nuevo, la sintonía de informativos.

Por su parte, Arturo Merayo destaca que debe tener una continuidad: "si es posible en nuevos flashes, y necesariamente en el más próximo boletín informativo, así como el informativo principal más cercano en el tiempo, se facilitarán los datos conocidos hasta el momento" (Merayo, 2000: 272).

El Flash no tiene periodicidad y, aunque por su carácter espectacular atrae al oyente, tampoco conviene abusar de él. 
Avance Informativo: Es, en esencia, un resumen de las noticias que se darán en otros informativos más extensos. Algunos estudiosos no lo incluyen en su clasificación, pero sí lo hace Francisco Sanabria que asegura que no debe confundirse con el flash, ya que el avance es un programa previsto por mínima que sea su duración, que casi siempre suele ser más amplia (Sanabria, 1994: 114). Este tipo de programas tiende a desaparecer para dar paso a los boletines horarios.

Boletín Horario: Es un programa de noticias que tiene una periodicidad fijada, normalmente las horas en punto o las horas y media, una duración corta -alrededor de cinco minutos-, y en el que se ofrecen de forma resumida las noticias más importantes. Además actualiza los hechos narrados en informativos anteriores. Es, en definitiva, una "recopilación breve de las noticias llegadas a la redacción entre dos períodos prefijados" (Muñoz y Gil, 1994: 83).

Los boletines presentan una estructura básica que consiste en: señales horarias; careta identificativa de los boletines; a continuación se dan directamente las noticias, y finaliza de nuevo con la careta. Generalmente, existe cierta jerarquización en las noticias, que pueden separarse a través de ráfagas o transiciones verbales. Algunas emisoras utilizan dos locutores para dar más ritmo a los boletines.

Informativo: Algunos autores lo denominan "diario hablado". En cualquier caso, son los programas informativos por excelencia. Su duración es mayor, de treinta a sesenta minutos. En él, no sólo se difunden noticias, sino que se analizan en profundidad. Para ello, se emplean diferentes géneros, sobre todo, las noticias y las crónicas. La mayor parte de las de emisoras tienen cuatro informativos principales: uno por la mañana (alrededor de las siete o las ocho), otro a mediodía (de dos a tres de la tarde), un informativo por la tarde (a las ocho habitualmente) y el último por la noche (entre las once y la una de la madrugada). Los informativos se identifican con un título propio, y suelen seguir esta estructura que establece Sanabria (1994: 117118):

\section{Sintonía.}

2. Señales horarias.

3. Entradilla. El locutor principal inicia el informativo con la noticia más importante del día.

4. Titulares. Se ofrecen cinco o seis noticias que luego se ampliarán. Con frecuencia se emplea doble titular (parecido a un título de prensa) es decir, un locutor presenta el tema, y un segundo locutor desarrolla brevemente ese tema.

5. Bloques. Se desarrollan las noticias agrupadas como se anticiparon en los titulares: internacional, nacional, economía, deportes, etc.

6. Pausas, con nuevo uso de la sintonía, normalmente cuando han pasado treinta minutos. Entonces, se pueden introducir titulares de lo ya abordado y de lo que se tratará a continuación.

7. Resolución. Resumen de las informaciones más destacadas.

8. Sintonía. 
Magazine: Es un programa de variedades en el que se mezcla la información con la opinión. Muñoz y Gil lo definen como programa informativo mixto, ya que, según ellos, "incluye un noticiario fragmentado, entre cuyas partes se emite publicidad, música, entrevistas extensas o coloquios" (Muñoz y Gil, 1994: 84). Además, poseen un título atractivo y se caracterizan por su larga duración, de dos a cinco horas. Los magazines pueden ser generales, en los que se tratan temas muy variados o especializados, generalmente, en deportes, toros o cultura.

En relación a las partes de la oración y los distintos lenguajes, la naturaleza de la radio exige que siempre tengamos que recurrir a la forma que sea más sencilla. Por esta razón, de varias palabras es conveniente elegir aquella que resulte más comprensible desde el punto de vista sonoro y conceptual. Los manuales de redacción recomiendan huir de las palabras compuestas y de las modas léxicas y sintácticas. Asimismo, el Manual de Español Urgente aconseja la variedad de vocabulario.

A continuación estudiamos el sustantivo como una de las partes de la oración, para redactar en radio, tanto su utilización correcta como los errores más frecuentes:

La regla general establece que debe utilizarse el nombre más concreto posible, así como evitar las palabras compuestas, las frases hechas y los neologismos, sobre todo los de origen político. Resulta incómodo al oído decir 'el colectivo de trabajadores' en vez de 'el grupo de trabajadores', o 'los trabajadores'. 'La audiencia' es peor que 'los oyentes'; 'el posicionamiento' pero que 'la actitud' o 'la postura'; y para decir que 'sí' a algo, no hace falta exclamar 'afirmativo' o 'positivo'.

Emilio Prado apunta algunas normas con respecto a la utilización de nombres poco comunes. Este autor sostiene que "los nombres poco conocidos o desconocidos deben incluirse tras el cargo o la descripción de la acción que les ha puesto de actualidad". Esta regla sólo se puede alterar, en opinión de Prado, cuando el nombre de la persona sea muy popular. A nuestro juicio, para que una información sea completa y rigurosa, siempre es conveniente que se ofrezca junto al nombre del protagonista o fuente de información, el cargo que ocupa o el hecho que le hace relevante.

En el mensaje radiofónico todo vocablo positivo se prefiere a su sinónimo negativo, sobre todo cuando ese sinónimo es homófono. Así, 'tristeza' es mejor antítesis de felicidad que el derivado 'infelicidad'. Esta norma se aplica a todas las partes de la oración. Por ejemplo, el verbo 'suspender' es más adecuado que 'no aprobar'. De esta forma se contribuye a la claridad del lenguaje y no provoca ninguna confusión en los oyentes.

En la práctica periodística, y por supuesto también en la radiofónica, existen una serie de usos incorrectos de nombres en cuanto a sus significados. Algunos ejemplos son:

1. Confrontación, en lugar de enfrentamiento. "El vocablo inglés confrontation ha confundido el uso de la palabra española 'confrontar', que en buen castellano equivale a 'cotejar' o 'comparar'" (Grijelmo, 1997: 422).

2. Distensión no es suavizamiento, sino una tensión violenta. Si hay distensión en un estado de cosas, se alteran, nunca se calman. 
3. Mandatario es el enviado, el que recibe un mandato; no es el que manda.

4. Evento no es sinónimo de hecho o acontecimiento, sino de eventualidad; es algo incierto, que puede ocurrir o no. Por tanto, son incorrectas las expresiones del tipo: 'El importante evento cinematográfico será en el hotel...'.

5. Periplo significa un gran recorrido geográfico.

6. Problemática se utiliza como adjetivo, no como sustantivo. Es un ejemplo de la tendencia a la progresiva nominalización del estilo en los medios de comunicación.

7. Saga es leyenda, no linaje o estirpe.

8. Singladura es el recorrido de un barco en 24 horas. Debe evitarse su utilización para cualquier viaje.

Los nombres extranjeros deben pronunciarse en su idioma, excepto aquellos que tengan una denominación en castellano usual, como es el caso de Londres. Lo que se considera incorrecto, aunque parezca una obviedad, es que los nombres combinen el castellano con otros idiomas, como por ejemplo 'el actor Roberto Taylor'. Por su parte, los autores coinciden en que sería exigible como norma el que dentro de cada emisora los nombres extranjeros tuvieran que sonar igual en la voz de todos los locutores, ya que transmitiría una idea de cohesión interna.

Dos cuestiones importantes dentro del apartado nombre son el género y el número. El Libro de Estilo de Onda Cero nos recuerda algunas consideraciones generales. En cuanto al género, se consideran femeninos los nombres de ciudades, pueblos, regiones o países acabados en a. Por su parte, las palabras que comienzan por a tónica llevan el artículo el, pero mantienen el género en todos los demás casos: 'el agua, pero las aguas, esta agua, el águila negra'. Además, conviene no confundir el género de palabras como 'atenuante', 'agravante' o 'eximente', que son femeninas y no masculinas.

Actualmente observamos en los medios de comunicación la diferencia lingüística entre hombres y mujeres, es decir, emplean 'señoras y señores', por ejemplo, en lugar de 'señores'. Esta oposición de género se realiza sobre todo para que no sean acusados de utilizar un lenguaje sexista. Sin embargo, en castellano, el género masculino se considera el término no marcado. De ahí que se utilice como género extensivo a los dos sexos.

No obstante, Luis Núñez Ladevéze ha escrito que "la Academia aconseja que los nombres profesionales que tradicionalmente se usaban como comunes dejen ahora de serlo y se flexionen en femenino y masculino" (45), como por ejemplo: 'abogado y abogada', 'médico y médica' o 'juez y jueza', aunque este último todavía es discutible.

Con respecto al número, tenemos que destacar que el plural de las palabras ter- 
minadas en vocal tónica distinta de -e, se construye en -es: 'esquís', 'israelíes', etc. No obstante, la tendencia real entre los hablantes es formar estos plurales con $s$, uso incorrecto pero generalizado. Los problemas se presentan en este apartado por la incorporación de extranjerismos, sobre todo anglicismos. Así, Núñez Ladevéze señala que "la dificultad más frecuente procede de la $t$ final inglesa o francesa y de la $m$ latina. La Academia propone como solución eliminar o completar la $t^{\text {" }}(47)$, mientras que en el caso de los latinismos u otros extranjerismos terminados en $-m$ se aconseja que se hispanicen en - 0 .

Los préstamos, o palabras tomadas de otras lenguas, ofrecen multitud de dudas. En este sentido, la Real Academia recomienda en lo posible su castellanización, aunque en muchas ocasiones este consejo no se corresponde con el uso real del hablante.

Estas matizaciones con respecto al número, nos sirven para abordar los problemas de vocabulario que proceden de los neologismos, que no son intrínsecamente malos, pero tampoco buenos sin discusión. En este sentido, Álex Grijelmo destaca que "el periodista que desee contribuir a que se mantenga el patrimonio común del idioma -un bien cultural que se ha de conservar con tanto esmero como los cuadros de Goya- buscará siempre palabras españolas que sustituyan a las que llegan de fuera y que empobrecen nuestro propio idioma" (Grijelmo, 1997: 422). Lo cual no quiere decir que el periodista deba cerrarse de pleno a todos los neologismos, ya que algunos son necesarios porque designan ideas o cosas nuevas ('bonobús', por ejemplo).

Tampoco faltan en este apartado los ejemplos de innovación lingüística, un procedimiento que para Núñez Ladevéze resulta innecesario y "casi siempre es contraproducente. Añade palabras nuevas más complicadas que otras palabras más sencillas a las que reemplazan" (56). Algunas innovaciones que este autor extrae de la prensa son: 'la concretización autoritaria de aquella filosofía'; 'Bandas de paramilitares siembran el terror en las calles de Panamá'; 'la precarización del empleo...', etc. Debido también a la traducción de lenguas extranjeras, y con el deseo de aparentar precisión y exactitud, cada día es más frecuente que los medios de comunicación cometan excesos con prefijos y sufijos. Ladevéze (58-63) recoge algunos casos significativos:

1. Prefijo sobre: por influencia del inglés tiende a sustituir al adverbio muy, y a veces a los prefijos re y super ('sobreexcitación').

2. Prefijo auto: aparecen palabras compuestas como 'autosuicidio' o 'autoinmolación'.

3. Sufijo miento: se abusa de él de forma generalizada, como por ejemplo: 'posicionamiento' o 'redimensionamiento' ('En estos momentos se está llevando un redimensionamiento de los servicios de RTVE...').

4. Sufijo ismo: es uno de los sufijos que, según Ladevéze, se ha puesto de moda entre los periodistas. A veces se abusa de él como en: 'victimismo', 'amiguismo', 'seguidismo' o 'alarmismo'.

5. Prefijo super: Núñez Ladevéze destaca que este prefijo sustituye con frecuencia al adverbio muy o "se usa innecesariamente cuando es redundante porque la palabra a la que se une ya incluye el significado enfático" (61), como por ejemplo: “España mantiene relaciones superprivilegiadas con el Reino de Marruecos'. 
6. Prefijo pre: en algunas ocasiones su uso enfático es innecesario. A veces se dice 'estamos discutiendo las precondiciones del contrato', cuando se trata simplemente de condiciones.

En conclusión, un programa radiofónico es un espacio de contenidos diversos, que posee una estructura interna propia y una duración concreta. De hecho, las grandes emisoras introducen en su programación magazines y en las tertulias se comentan temas de actualidad, a mitad de camino entre la información y la opinión.

Las circunstancias psicológicas a las que está expuesto el oyente de radio son muy distintas a las específicas de los destinatarios de mensajes transmitidos a través de medios audiovisuales. El oyente normalmente recibe el mensaje en soledad y el emisor puede permitirse dar una forma tal al mensaje que parece que está transmitido única y exclusivamente para un único sujeto individual. Esta cercanía psicológica, que se asienta también en el uso del lenguaje de base oral, explica, por ejemplo, el tuteo del emisor en algunas ocasiones y la confianza con que el receptor se pone en contacto con la emisora de radio.

Como decíamos al principio, el lenguaje que usan los periodistas en todos los medios de comunicación ha preocupado a los estudiosos; un tema que continúa en la brecha y, en realidad, los estudiosos del idioma y el mundo periodístico en muy pocas ocasiones se han puesto de acuerdo porque, cada uno tiene sus intereses y sus puntos de vista.

No hay emisora que no tenga su propio libro de estilo, o un libro adaptado a la emisora. Otra cosa es que se ponga más en práctica o menos lo que ese libro de estilo recoge: cómo una emisora puede hacer un uso más correcto del lenguaje y otra hace un uso más incorrecto y, en fin, cómo van saliendo adelante en relación con la forma de expresarse, en relación con la expresión de los contenidos.

Podemos tener muchísima información sobre un tema y luego no saber contarlo o tener muy poca y sacarle mucho partido y esto queda demostrado, por supuesto, en los medios de comunicación, sobre todo, los audiovisuales.

La gran preocupación de los medios de comunicación y de las emisoras de radio ha sido el lenguaje como instrumento de trabajo; cuidar de ese lenguaje y para eso casi siempre se ha echado mano de los libros de estilo. Éstos en la mayoría de los casos han ayudado a caminar a las emisoras, porque está claro el hecho de que en una emisora se hable no se escriba, porque se escribe para prensa.

En las emisoras lo que se hace habitualmente es escribir para leer, escribir para contar cosas. Hay veces que esta escritura se piensa que no es tan relevante, pero eso no indica que el uso del lenguaje no sea correcto. El lenguaje debe ser correcto, igualmente, pero la realidad demuestra que puede haber incorrecciones lingüísticas o gramaticales.

En el uso del lenguaje radiofónico, hay otro tipo de deformaciones también. Hay errores de contenido en cuanto a desinformación, en cuanto a deformación de los mensajes, en cuanto manipulaciones, en cuanto a persuasiones un tanto gratuitas y 
en muchos de los casos, en realidad, lo que subsiste son ambigüedades ideológicas del propio emisor de ese mensaje, del propio periodista, locutor que en definitiva repercute en ofrecer una información más o menor veraz, que al final, el producto que uno espera recibir sea una información correcta, rigurosa, que se aproxime lo más exactamente posible a lo que ha sucedido.

Porque, es un lenguaje neutro, y dentro de eso, intentar que sea un lenguaje lo más lineal posible y, en resumidas cuentas, que la información sea lo más veraz que se pueda, aunque todo está condicionado por el uso del lenguaje que haga un señor determinado.

En definitiva, la mayoría de los errores de lenguaje se deben a que los mensajes radiofónicos frecuentemente no se ajustan a las normas lingüísticas, sino que tratan de 'maquillar' el lenguaje coloquial con recursos que les otorga cierta distinción. Para ello, se emplean locuciones prepositivas, circunloquios, frases largas, etc. Se piensa que con estas fórmulas se ejerce mejor la profesión, pero realmente lo que se hace es dificultar la comprensión a los receptores.

\section{REFERENCIAS BIBLIOGRÁFICAS}

CEBRIÁN HERREROS, M. (1983). La mediación técnica de la información radiofónica. Barcelona: Mitre.

- (1992). Géneros informativos audiovisuales: radio, televisión, periodismo gráfico, cine, vídeo. Madrid: Ciencia 3.

- (1994). Información radiofónica. Mediación técnica, tratamiento y programación. Madrid: Síntesis.

CHILLÓN, L.A. La literatura de fets. Barcelona: Libergraf, 1994

FAUS, Á. La radio: introducción a un medio desconocido. Madrid: Latina Universitaria, 1974, 1981.

FIGUEROA, R. ¡Qué onda con la radio! México: Longman de México, 1996.

GOMIS, L. Teoría dels generes periodístics. Barcelona: Centre d'Investigació de la Comunicació, 1989.

GONZÁLEZ, N. La interpretación y la narración periodísticas. Pamplona: Eunsa, 1997.

GONZÁLEZ CONDE, M.J. Comunicación radiofónica. De la radio a la universidad. Madrid: Editorial Universitas, 2001.

GRAÑA, M. La escuela de periodismo: programas y métodos. Madrid: Compañía Ibero-Americana de Publicaciones, 1930.

GRIJELMO, Á. El estilo del periodista. Madrid: Grupo Santillana de ediciones, 1997.

GUTIÉRREZ, M. y PERONA, J.J. Teoría y técnica del lenguaje radiofónico. BarceIona: Bosch Comunicación, 2002. 
MARTíN VIVALDI, G. Géneros periodísticos. Madrid: Paraninfo, $1^{\text {a }}$ edición, 1987.

MARTÍNEZ-COSTA, M.P. El narrador en radio. Voz presente y relatos polifónicos. En IMÍZCOZ, T. (et. al). Quién cuenta la historia. Estudios sobre el narrador en los relatos de ficción y no ficción. Pamplona: Eunate, 1999.

MARTÍNEZ-COSTA, M.P. y DIEZ UNZUETA, J.R. Lenguaje, géneros y programas de radio. Pamplona: Eunsa, 2005.

MARTÍNEZ-COSTA, M.P. y HERRERA, S. "Los géneros radiofónicos en la teoría de la redacción periodística en España. Luces y sombras de los estudios realizados hasta la actualidad". Comunicación y sociedad, XVII, nº 1, pp. 115-143, 2004.

MERAYO, A. Para entender la radio. Salamanca: Publicaciones Universidad Pontificia de Salamanca, $2^{\mathrm{a}}$ edición, 2000.

MERAYO, A. y PÉREZ ÁlVAREZ, C. La magia radiofónica de las palabras. Salamanca: Librería Cervantes, 2001.

MUÑOZ, J.J. y GIL, C. La radio: teoría y práctica. Madrid: Instituto Oficial de Radio y Televisión, $2^{\text {a }}$ edición, 1994.

MUÑOZ, J.J. Redacción periodística. Salamanca: Librería Cervantes, 1994.

NÚÑEZ LADEVEZE, L. Introducción al periodismo escrito. Barcelona: Ariel Comunicación, 1995.

PEDRERO, L.M. La programación informativa en la radio generalista. En MARTíNEZ-COSTA, M.P. (2002). Información radiofónica. Cómo contar noticias en la radio hoy. Barcelona: Ariel Comunicación, pp. 263-286, 2002.

PEÑAFIEL, C. La información en la radio. En MARTíNEZ-COSTA, M.P. (coord.). Información radiofónica. Cómo contar noticias en la radio hoy. Barcelona: Ariel Comunicación, pp. 21-57, 2002.

SOENGAS, X. Informativos radiofónicos. Madrid: Cátedra, 2003.

\section{Breve semblanza de la autora}

Pastora Moreno es Profesora Titular de Redacción Periodística del Departamento de Periodismo II, de la Universidad de Sevilla, con ejercicio docente en la Facultad de Comunicación de la Hispalense. Doctora en Filología Hispánica (1992) y en Ciencias de la Información (1996) por la Universidad de Sevilla, su labor docente se ha extendido más allá de su titularidad en dicho centro y, de este modo, ha sido profesora visitante en diversas universidades europeas (Bruselas, Bolonia, Milán y Verona), así como en la Universidad Nacional de Chengchi en Taipei (República China de Taiwán). Además, ha impartido cursos en la Universidad de Mérida-Yucatán (México), Universidad de las Américas (Puebla), Universidad Autónoma de Chihuahua, Universidad de San Salvador, Radiotelevisión de Veracruz, Universidad Veracruzana, Universidad Anahuac de Cancún, Universidad de La Habana. 